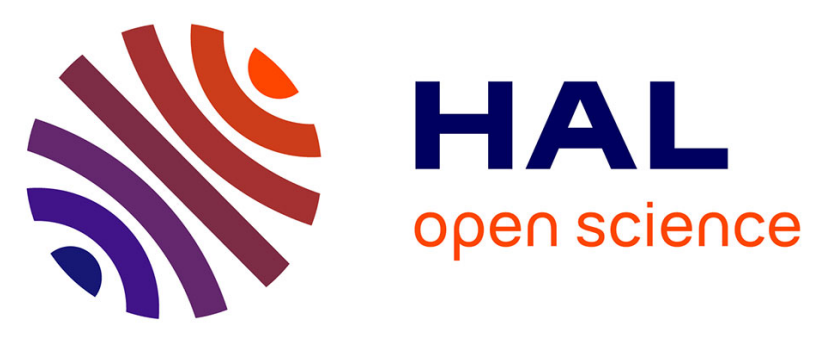

\title{
Genetic variation for growth, morphological, and physiological traits in a wild population of the Neotropical shade-tolerant rainforest tree Sextonia rubra (Mez) van der Werff (Lauraceae)
}

Ivan Scotti, Leticia Calvo-Vialettes, Caroline Scotti-Saintagne, Maurizio

Citterio, Bernd Degen, Damien Bonal

\section{To cite this version:}

Ivan Scotti, Leticia Calvo-Vialettes, Caroline Scotti-Saintagne, Maurizio Citterio, Bernd Degen, et al.. Genetic variation for growth, morphological, and physiological traits in a wild population of the Neotropical shade-tolerant rainforest tree Sextonia rubra (Mez) van der Werff (Lauraceae). Tree Genetics and Genomes, 2010, 6 (2), pp.319-329. 10.1007/s11295-009-0251-8 . hal-01032145

\section{HAL Id: hal-01032145 \\ https://hal.science/hal-01032145}

Submitted on 30 May 2020

HAL is a multi-disciplinary open access archive for the deposit and dissemination of scientific research documents, whether they are published or not. The documents may come from teaching and research institutions in France or abroad, or from public or private research centers.
L'archive ouverte pluridisciplinaire HAL, est destinée au dépôt et à la diffusion de documents scientifiques de niveau recherche, publiés ou non, émanant des établissements d'enseignement et de recherche français ou étrangers, des laboratoires publics ou privés. 


\title{
Genetic variation for growth, morphological, and physiological traits in a wild population of the Neotropical shade-tolerant rainforest tree Sextonia rubra (Mez) van der Werff (Lauraceae)
}

\author{
Ivan Scotti • Leticia Calvo-Vialettes • \\ Caroline Scotti-Saintagne • Maurizio Citterio • \\ Bernd Degen • Damien Bonal
}

Received: 7 January 2009 /Revised: 28 October 2009 /Accepted: 2 November 2009/Published online: 15 December 2009

(C) Springer-Verlag 2009

\begin{abstract}
Quantitative genetic diversity is a fundamental component of the interaction between natural populations and their environment. In breeding programmes, quantitative genetic studies on tropical trees have so far focused on fast-growing, light-demanding species, but no information exists on shade-tolerant, slow-growing species. For this study, 27 3-year-old open-pollinated families of the Neotropical shade-tolerant rainforest tree Sextonia rubra were measured in semicontrolled conditions for 20 morphological, growth, and photosynthesis traits; the effect of genetic relatedness, habitat of provenance, and mother tree status on seedling traits was analysed. Nine traits displayed significant genetic effects, while mother tree status and habitat effects were not significant $(P>0.05)$ for an y trait. Estimated heritability varied between 0.14 and 0.28 , with
\end{abstract}

Communicated by R. Burdon

Electronic supplementary material The online version of this article (doi:10.1007/s11295-009-0251-8) contains supplementary material, which is available to authorized users.

I. Scotti $(\bowtie) \cdot$ C. Scotti-Saintagne $\cdot$ D. Bonal

INRA—Unité Mixte de Recherche "Ecologie des Forêts de Guyane",

97387 Kourou, French Guiana

e-mail: ivan.scotti@ecofog.gf

L. Calvo-Vialettes

AgroParisTech-Unité Mixte de Recherche

"Ecologie des Forêts de Guyane",

97387 Kourou, French Guiana

M. Citterio

CIRAD - Unité Mixte de Recherche "Ecologie des Forêts de Guyane",

97387 Kourou, French Guiana growth-related traits having the highest values. Additive genetic variation correlated positively with nonheritable variation, suggesting that ecological-evolutionary factors increasing or decreasing additive genetic variance may also affect nonheritable variation in the same direction. Our results suggest that quantitative genetic variability should be taken into account in ecological studies on, and in the management of, natural tropical rainforests; further research is needed to investigate genetic $\times$ environment interactions, in particular from the point of view of the genetic response of shade-tolerant plant species to variations in light availability.

Keywords Ecophysiological traits · Heritability · Guiana shield $\cdot$ Amazon $\cdot$ Ecological genetics

\section{B. Degen}

Johann Heinrich von Thünen-Institut,

Bundesforschungsinstitut für Ländliche Räume,

Wald und Fischerei,

Institut für Forstgenetik,

22927 Grosshansdorf, Germany

Present Address:

L. Calvo-Vialettes

Rainforest Alliance Inc. Programme SmartWood,

C/Arganda, 36, bajo izq,

28005 Madrid, Spain 


\section{Introduction}

Growth and survival of seedlings are crucial factors in rainforest regeneration processes, and the traits underlying the outcome of these processes are of paramount importance in the evaluation of forest dynamics at early stages. The response of seedlings to environmental conditions varies among species and determines the capability of each species to establish in a given habitat (Baraloto et al. 2006; Baraloto et al. 2005; Poorter and Markesteijn 2008; Sterck et al. 2006). It can be argued that intraspecific variation also has an impact in determining population dynamics; partitioning the heritable and nonheritable components of this variation is central to the understanding of population processes. On one hand, from an evolutionary standpoint, genetic variation for these traits, if present, implies that within-species diversity may have an impact on the rate at which different populations, or individuals within populations, can achieve successful establishment. Although the vast majority of seedlings disappear in the early developmental stages (Augspurger and Kitajima 1992), small but significant fitness differences can accumulate over generations and within cohorts and lead to changes in trait and population fitness means. On the other hand, forest management can only rely upon juvenile traits to provide guidelines for the selection of germplasm in afforestation programmes. Much effort is therefore devoted to the estimation of genetic parameters and of their stability in juvenile forest tree populations (for recently published examples, see Bundock et al. (2008), Callister and Collins (2008), Ward et al. (2008), Sotelo Montes et al. (2007), Wightman et al. (2007), and references therein). Assessment of the amount and distribution of quantitative genetic diversity is therefore an important goal both for ecological studies and for forest management.

This study deals with the evaluation of variability and heritability of traits related to morphology, growth, and photosynthesis, which represent key features that characterise plant investment in light interception and $\mathrm{CO}_{2}$ acquisition. The study was carried out in open-pollinated families of 3-year-old seedlings of the tropical rainforest tree Sextonia rubra (Mez) van der Werff (Lauraceae), a shade-tolerant, hermaphroditic, insect-pollinated Amazonian species. Unlike light-demanding, fast-growing tropical species, which are the historical focus of breeding and provenance tests, shade-tolerant, slow-growing trees have not received much attention from geneticists, yet they represent a substantial portion of the trees in undisturbed tropical rainforests (Favrichon 1994). S. rubra is a typical shade- tolerant species, and studying its genetic variation may provide a preliminary understanding of the genetic dynamics of tree populations in pristine forests. In its turn, the genetic basis of traits has historically been disregarded as a factor contributing to the lush diversity of tropical rainforests, the study of which has rather focused on species diversity and the effect of environmental conditions on plant life. With this paper, we intend to start filling this double gap. The study focuses on a single population of S. rubra, located at Paracou, French Guiana, chosen because its population genetic properties and inbreeding structure have been previously characterised (Hardy et al. 2006; Veron et al. 2005). The available information on its mating system and on the spatial distribution of genetic variation was combined in order to estimate quantitative genetic parameters. The results presented here show that traits vary in their genetic diversity and heritability; that mother tree habitat has an effect on at least some seedling traits; that, although confidence intervals for parameter estimates are large, a trend emerged between the observed amounts of additive genetic variation and nonheritable variation; and that neutral molecular markers are poor predictors of quantitative trait variation.

\section{Materials and methods}

A total of 900 seedlings from 30 open-pollinated families of $S$. rubra were grown in a shadehouse in Kourou, French Guiana, under semicontrolled environment conditions. One layer of black shade cloth was used to reduce light levels to about $10.7 \pm 2.8 \%$ of full sun. This light level was higher than light conditions usually met by young $S$. rubra seedlings in natural conditions, but was chosen because it allowed the seedlings to display a reasonable growth over the study period (Barigah et al. 1998). Mean air temperature and relative humidity in the shadehouse were $27.8 \mathrm{C}$ (minimum (min)/maximum (max): $23.6 \mathrm{C} / 31.7 \mathrm{C}$ ) and $70 \%$ (min/max: 52\%/98\%), respectively. Twenty-litre pots were filled with a mixture of sand $(30 \%)$ and an A horizon soil $(70 \%)$ from the natural forest. Soil water content was maintained near field capacity $\left(\approx 0.25 \mathrm{~m}^{3} \mathrm{~m}^{-3}\right)$ by watering the plants three times a week. The seedlings were treated with a commercial insecticide (Cuberol: 5\% rotenone) whenever needed. The experimental design consisted of 30 randomised complete blocks each containing one seedling per family; randomisation permits taking into account microenvironmental variations in shadehouse.

After 3 years of growth in the shadehouse, realised survival was $51 \%$, so that only 450 seedlings from 27 families could be measured. There was no significant difference in survival rates among families (Fisher's exact test between the families with the most extreme survival rates, odd ratio $=0.42, P$ value $=0.08$ ). Mortality occurred generally soon after germination, but no specific cause could be identified. A total of 20 traits were then measured including growth, morphological, and photosynthetic variables (Table 1). These traits were selected because they are key features that characterise plant investment in light interception and $\mathrm{CO}_{2}$ and water acquisition and utilisation. 
Leaf thickness was measured using a digital micrometre (Mitutoyo Corporation Inc., Aurora, IL, USA) at three positions on the leaf lamina. Leaf mass per unit area (LMA) was calculated based on the lamina surface and its dry mass (drying to constant mass for $72 \mathrm{~h}$ at $60 \mathrm{C}$ ). A semiquantitative index of chlorophyll content (ICC, SPAD unit) was obtained for each leaf using a chlorophyll metre (SPAD-502, Konica Minolta Sensing Inc., NJ, USA). Net photosynthetic rate (PHRA, micromole $\mathrm{CO}_{2} \mathrm{~m}^{-2} \mathrm{~s}^{-1}$ ) was obtained using a portable photosynthesis system (CIRAS1, PP-Systems, Hoddesdon, UK) operating in open mode and fitted with a Parkinson leaf cuvette. Gas exchange measurements were conducted under the following nonlimiting and light-saturating environmental conditions (Coste et al. 2005): photosynthetic active radiation $(\mathrm{PAR})=599 \pm 4 \mu \mathrm{mol} \mathrm{m} \mathrm{s}^{-1}$, vapour pressure deficit $=1.6 \pm 0.3 \mathrm{kPa}$, and air temperature $=$ $30.8 \pm 1.2$ C. In addition, for each seedling, average leaf health status (from fully green to yellow) was recorded. For each block, shadehouse light intensity was obtained using a linear PAR ceptometre (AccuPar, Decagon Devices, Pullman, WA, USA) and a reference light sensor (Quantumeter Li190SB, Licor, Lincoln, Ne, USA) located outside the shadehouse. Where possible, the same trait was measured on different copies of the same organ (e.g. leaves) in order to assess the stability of the estimates of genetic parameters. After all measurements were performed, plants were harvested, and aboveground dry biomass was obtained after drying leaves and stems to constant mass $(72 \mathrm{~h}$ at $60 \mathrm{C})$.

Two types of covariates were included in the analyses to represent mother tree status in the forest population and mother tree ecological habitat. Mother tree diameter was used as an estimator of the access of each adult tree to light resources, with the assumption that larger trees occupy a more dominant position in the canopy and therefore have better access to sunlight; mother tree location relative to local topography ("habitat", classified as "seasonally flooded", "slope" and "terra firme") was used as an environmental covariate, combining soil nutrient composition and texture, drainage characteristics, and light environment. Seed mass, on the contrary, was not considered as a relevant cofactor for two reasons. First, dry weight of $S$. rubra seeds was on average close to $1 \mathrm{~g}$ (Hardy et al. 2006), that is, around 7\% of the average biomass of 3-yearold seedlings (this study); secondly, independent data on other species (Eperua spp.; Scotti et al. in preparation) show that seed mass effects on seedling traits disappear

Table 1 Description of traits and descriptive statistics for each trait

\begin{tabular}{|c|c|c|c|c|c|c|c|}
\hline Trait & Description & Unit of measure & Min & Mean & Max & $\mathrm{CV}$ & Transformation \\
\hline \multicolumn{8}{|c|}{ Leaf traits } \\
\hline L1SH & Shape (width/length), 1st leaf from apical meristem & Adimensional & 0.168 & 0.270 & 0.428 & 0.110 & Ln \\
\hline L2SH & Shape (width/length), 2nd leaf from apical meristem & Adimensional & 0.167 & 0.267 & 0.439 & 0.100 & $\mathrm{Ln}$ \\
\hline L3SH & Shape (width/length), 3rd leaf from apical meristem & Adimensional & 0.172 & 0.266 & 0.445 & 0.104 & Ln \\
\hline L1TH & Thickness, 1st leaf from apex & $\mathrm{mm}$ & 0.96 & 1.82 & 2.72 & 0.170 & - \\
\hline L2TH & Thickness, 2nd leaf from apex & $\mathrm{mm}$ & 1.00 & 1.87 & 3.04 & 0.174 & - \\
\hline L3TH & Thickness, 3rd leaf from apex & $\mathrm{mm}$ & 0.98 & 1.90 & 3.65 & 0.113 & $\mathrm{Ln}$ \\
\hline L1MA & Mass per unit area, 1st leaf from apex & $\mathrm{g} \mathrm{cm}^{-2}$ & 11.8 & 71.5 & 130 & 0.214 & - \\
\hline L2MA & Mass per unit area, 2nd leaf from apex & $\mathrm{g} \mathrm{cm}^{-2}$ & 10.2 & 74.8 & 119 & 0.195 & - \\
\hline L3MA & Mass per unit area, 3rd leaf from apex & $\mathrm{g} \mathrm{cm}^{-2}$ & 37.7 & 77.6 & 121 & 0.173 & - \\
\hline L1SP & Length of leaf apex, 1st leaf from apical meristem & $\mathrm{cm}$ & 0 & 0.465 & 2.90 & 0.671 & - \\
\hline L2SP & Length of leaf apex, 2nd leaf from apical meristem & $\mathrm{cm}$ & 0 & 0.390 & 2.80 & 0.345 & $\sqrt{ }$ \\
\hline \multicolumn{8}{|c|}{ Growth traits } \\
\hline HEIG & Height & $\mathrm{cm}$ & 8.00 & 36.3 & 118 & 0.110 & $\mathrm{Ln}$ \\
\hline DIAM & Diameter at stem base & $\mathrm{mm}$ & 2.95 & 8.78 & 18.5 & 0.155 & $\sqrt{ }$ \\
\hline NULV & Number of leaves & Adimensional & 1 & 15 & 71 & 0.170 & 4 \\
\hline $\mathrm{BIOM}$ & Above ground biomass & $\mathrm{g}$ & 0.39 & 15.1 & 143 & 0.448 & Ln \\
\hline LFAR & Total leaf area & $\mathrm{cm}^{2}$ & 8.73 & 819 & 6970 & 0.205 & 4 \\
\hline \multicolumn{8}{|c|}{ Photosynthesis traits } \\
\hline PHRA & Net photosynthetic rate & $\mu \mathrm{molCO} 2 \mathrm{~m}^{-2} \mathrm{~s}^{-1}$ & 1.30 & 5.07 & 11.5 & 0.393 & - \\
\hline $\mathrm{L} 1 \mathrm{CC}$ & Chlorophyll content index, 1st leaf from apex & SPAD unit & 87.5 & 424 & 831 & 0.292 & - \\
\hline $\mathrm{L} 2 \mathrm{CC}$ & Chlorophyll content index, 2nd leaf from apex & SPAD unit & 137 & 456 & 877 & 0.246 & - \\
\hline $\mathrm{L} 3 \mathrm{CC}$ & Chlorophyll content index, 3rd leaf from apex & SPAD unit & 181 & 484 & 779 & 0.256 & - \\
\hline
\end{tabular}

Min, Mean, Max absolute individual seedling minimum, average, and maximum trait values, respectively, $C V$ coefficient of variation 
after 1 year, even if the seeds are much more substantial $(10-100 \mathrm{~g})$ than $S$. rubra's.

Information about the level of inbreeding in the families was previously estimated based on five microsatellites markers (Veron et al. 2005). Molecular marker data are represented by the data set published by Veron et al. (2005) completed with further genotyping in order to obtain a larger data set.

Data handling, preliminary statistical analyses of phenotypic data (mean, variance, correlations), calculation of residuals, tests of significance of effects, and estimation of parameters by restricted maximum likelihood were performed using the STAT and NLME packages in R (http://www.r-project.org). Credible intervals for total variance (that is, the expected variance of the population our families are drawn from) were computed by a Bayesian approach using OpenBUGS (http:// www.mrc-bsu.cam.ac.uk/bugs), based on the same linear model as in maximum likelihood analyses, with a burn-in of 100,000 iterations and one million iterations for calculations. Quantitative trait data were checked for normality (Shapiro test) and transformed where needed (Table 2). Generally speaking, with the exception of leaf thickness and length of leaf apex (that is, the narrow, elongated end of each lamina), the same transformation was applied to homologous traits. Leaf apex length showed a semiquantitative distribution, with approximately one third of the seedlings having no apex. For quantitative analyses of this trait, only seedlings showing a nonzero apex length were considered. Globally, data transformation (logarithmic, square-, or fourth root) was applied for ten out of 20 traits. Analysis of variance (ANOVA) was applied to check for the effect of mother tree habitat on seedling traits. Regression analysis was applied to the identification of the effect of mother tree diameter at breast height (DBH) on seedling traits.

In addition, for photosynthetic rate which displayed significant correlation with microvariations of light intensity in the shadehouse, residuals of the regression of photosynthetic rate against shadehouse light intensity were used in the following analyses.

The subdivision of the phenotypic value $(P)$ of a seedling can be obtained with the following model:

$P=\mu+F+B+\mathrm{LC}+\mathrm{HA}+S$

with $\mu$ the population mean, $F$ the family effect, $B$ the block effect, LC the leaf colour effect, HA mother tree habitat effect, and $S$ the seedling effect.

The mixed linear model was used to estimate withinfamily variance due to seedling effect $S\left(\sigma_{\mathrm{S}}{ }^{2}\right)$, among-families variance due to family effect $F\left(\sigma_{\mathrm{F}}^{2}\right)$, and their $95 \%$ confidence intervals, by restricted maximum likelihood, using the NLME package in R. Here, families and seedling are random effects, and all other factors are fixed effects, with families nested within habitats. Normality of ANOVA residuals was checked (Bartlett test for normality of residuals).

Estimation of among-families variance $\left(\sigma_{\mathrm{F}}^{2}\right)$ was then used to estimate the proportion of additive variance in the population. In a set of open-pollinated families, randomly drawn from a panmictic population, the following relationship holds between the additive part of the genetic variance $\left(\sigma^{2} \mathrm{~A}\right)$ and the variance of family means $\left(\sigma_{\mathrm{F}}^{2}\right)$

$\sigma_{F}^{2}=\frac{1}{4} \sigma_{A}^{2}$.

Table 2 Results of ANOVA analyses for traits displaying significant family effects

\begin{tabular}{|c|c|c|c|c|c|c|c|}
\hline & $\mathrm{Df}$ & Mean Sq & $P(>F)$ & Mean Sq & $P(>F)$ & Mean Sq & $P(>F)$ \\
\hline & & L1TH & & L3TH & & NULF & \\
\hline Block & 11 & 0.019 & $<0.0001^{* * *}$ & 0.615 & $<0.0001 * * *$ & 0.180 & $0.03 *$ \\
\hline Leaf health status & 6 & 0.0002 & 0.83 & 0.011 & 0.79 & 0.136 & 0.18 \\
\hline Family & 24 & 0.0009 & $0.01 *$ & 0.033 & $0.03 *$ & 0.167 & $0.01 *$ \\
\hline \multirow[t]{2}{*}{ Residuals } & & 0.0005 & & 0.019 & & 0.092 & \\
\hline & & Biomass & & Diameter & & Height & \\
\hline Block & 11 & 2.53 & $0.0005 * * *$ & 0.307 & 0.13 & 0.471 & $0.0004 * * *$ \\
\hline Leaf health status & 6 & 1.49 & 0.09 & 0.168 & 0.56 & 0.056 & 0.90 \\
\hline Family & 24 & 1.54 & $0.007 * *$ & 0.446 & $0.001 * *$ & 0.347 & $0.0005 * * *$ \\
\hline \multirow[t]{2}{*}{ Residuals } & $232-295$ & 0.805 & & 0.206 & & 0.149 & \\
\hline & & Area & & $\mathrm{L} 1 \mathrm{CC}$ & & $\mathrm{L} 2 \mathrm{CC}$ & \\
\hline Block & 11 & 5.47 & $<0.0001^{* * *}$ & 18459 & 0.15 & 19949 & 0.11 \\
\hline Leaf health status & 6 & 3.09 & $0.02 *$ & 51835 & $0.0006^{* * *}$ & 49868 & $0.0009 * * *$ \\
\hline Family & 24 & 2.05 & $0.03 *$ & 20442 & $0.04 *$ & 22953 & $0.01^{*}$ \\
\hline Residuals & $232-295$ & 1.22 & & 12709 & & 12818 & \\
\hline
\end{tabular}

$D f$ Degrees of freedom; Means sq Mean square; ${ }^{*} P=0.05 ; * * P=0.01 ; * * * P=0.001$ (significance of effects was tested against residual variance by Fisher's $F$ test) 
Information on the genetic structure of the population under study (Hardy et al. 2006; Veron et al. 2005) was used as follows: First, the following relation holds in comparisons of populations with and without inbreeding:

$\sigma_{A^{*}}^{2}=(1+F) \sigma_{A}^{2}$

where $A^{*}$ is the additive genetic variance estimated with inbreeding, and $F$ is the inbreeding coefficient (Lynch and Walsh 1998, chapter 4). Given that in the studied population $F=0.076$ (Hardy et al. 2006), the estimates of additive genetic variance estimated from variance among families were corrected by multiplying them by a factor of $1 /(1+F)=1 / 1.076$.

Next, in the calculation of narrow-sense heritability, the presence of a mixture of full sibs and half sibs in the progenies (Veron et al. 2005) was taken into account to correct the relatedness of siblings. Narrow-sense heritability $\left(h^{2}\right)$ was estimated as

$\widehat{h_{S}^{2}}=\frac{4 \widehat{\sigma_{F}^{2}}}{\widehat{\sigma_{F}^{2}}+\widehat{\sigma_{S}^{2}}}$

with strictly half sib families. The factor 4 in the numerator, used for pure half-sib families (Eq. 4), was replaced by a factor $(0.9 \cdot 4)+(0.1 \cdot 2)=3.8$, that takes into account that $90 \%$ of the siblings are half sibs, and $10 \%$ are full sibs (Veron et al. 2005). Finally, a third violation of model assumptions is represented by differentiation of pollen clouds on the study site (Veron et al. 2005), amounting to $F_{\mathrm{ST}}=0.06$. The differentiation of pollen clouds inflates the apparent genetic differentiation among mother trees by a factor equal to $0.5 \cdot F_{\mathrm{ST}}$, where 0.5 represents the contribution by the pollen cloud to progeny genotypes. Therefore, the estimated $\sigma^{2} \mathrm{~A}$ was further reduced by a factor $0.5 \cdot 0.06=0.03$. The combination of these three corrections led to the estimation of $\widehat{\sigma_{A}^{2}}=3.43 \widehat{\sigma_{F}^{2}}$. This correction was applied in all subsequent calculations.

In order to break apart the roles of heritable and nonheritable (dominance, epistasis, and residual) variability on the observed heritability values, coefficients of genetic and residual variation (including all nonheritable sources of variation) were calculated based on most likely estimates of variance components and on their confidence intervals. Coefficients of additive genetic variation (AGCV) were estimated by dividing the square root of $\widehat{\sigma_{A}^{2}}$ by trait mean, and a "residual" equivalent of AGCV, called "coefficient of residual variation" ( $\mathrm{RCV}$ ) was estimated as:

$\widehat{\mathrm{RCV}}=\frac{\sqrt{\widehat{\sigma_{F}^{2}}+\widehat{\sigma_{S}^{2}}-\widehat{\sigma_{A}^{2}}}}{\bar{x}}$,

where $\widehat{\sigma_{F}^{2}}$ and $\widehat{\sigma_{S}^{2}}$ are the maximum likelihood estimates of among-families and within-family variances, and $x$ is trait mean. RCV is the sum of all nonheritable (narrow sense) sources of variation (dominance, epistasis, and residual).

Considering the quantity $\left(\sigma_{F}^{2}+\sigma_{S}^{2}\right)$ as a constant representing the (true) total population genetic variance, it is easy to show that AGCV and RCV are related to each other by the equation:

$\mathrm{AGCV}^{2}+\mathrm{RCV}^{2}=\frac{\sigma_{F}^{2}+\sigma_{S}^{2}}{\bar{x}^{2}}$

and that, consequently, it is possible to construct a joint confidence interval for the two coefficients of variation under the constraint of constant total variance. With the same argument, it is possible to show that ACGV and narrow-sense heritability $\left(h^{2}\right)$ are related by the following equation:

$h^{2}=\frac{\bar{x}^{2}}{\sigma_{F}^{2}+\sigma_{S}^{2}} \mathrm{AGCV}^{2} ;$

therefore, it is also possible to construct a joint confidence interval for estimated heritability and coefficient of genetic variation. These equations were used for computing and plotting joint confidence intervals of parameters based on restricted maximum likelihood estimates of confidence intervals for $\sigma_{F}^{2}$ and $\sigma_{S}^{2}$.

Phenotypic correlations were estimated based on individual values using Pearson coefficients. Genetic correlations were estimated based on correlation between best linear unbiassed prediction (BLUP)-estimated genetic (family) effects (Lynch and Walsh 1998) using Spearman coefficients. Statistical significance of estimates of genetic correlation was tested by a bootstrap approach. For each pair of traits, one thousand bootstrapped samples were obtained by drawing genetic effects with replacement, and correlation was estimated for each sample. The values were ranked, and the values corresponding to the 0.025 and the 0.975 quartiles of the distribution were taken as the confidence limits for the true value of the correlation coefficient (corresponding to a two-tailed test with a $P=0.05$ threshold). The coefficients were considered as significant when the confidence interval did not encompass zero.

The relationship between trait values and genotypes at neutral (SSR) markers was investigated in order to assess the usefulness of SSR genotyping as a predictor of quantitative trait properties.

\section{Results}

Mean and individual minimum and maximum observed values for each trait, along with their coefficients of variation, are reported in Table 1 for comparison with other studies. 
Globally, values differed significantly when the same trait was measured on the first, second, and third leaf from apical meristem (Student's $t$ tests significant at $P=0.05$ for all comparisons except for leaf shape and for second and third leaf thickness). In one case (leaf thickness), the shape of trait distribution differed markedly between leaves (not shown). Due to these differences, same traits measured on different leaves were treated separately. Among leaf traits, length of leaf apex gave the largest coefficient of variation $(\mathrm{CV}=0.67$ and $\mathrm{CV}=0.35$ for the first and second leaf from apex, respectively) compared (1) to leaf shape where $\mathrm{CV}$ is 0.1 ; (2) to thickness for which CV varied from 0.11 to 0.17 ; and (3) to mass per unit area where CV varied from 0.17 to 0.21 .

Among growth traits, aboveground biomass was the most variable trait $(\mathrm{CV}=0.45)$ with strong differences between the minimum and maximum value observed for a single seedling ( 0.39 and $143 \mathrm{~g}$, respectively). Such strong differences between individual seedling values was also observed for other growth traits such total leaf area, height, and number of leaves.

In order to evaluate possible maternal and environmental effects on seedling trait values (that is, either environmental conditions affecting mother trees, and therefore seeds, or the action of genes being expressed in mother trees and having an influence on the seeds), two types of data were considered: mother tree habitat and mother tree DBH. No traits showed significant habitat effects, or a correlation with mother tree DBH, although several traits showed a marginally significant test (not shown). Photosynthetic rate was strongly dependent on microvariations in shadehouse light intensity, and therefore, residuals of correlation between photosynthetic rate and shadehouse light intensity were used for subsequent analyses.

Possible interactions between each factor (including family) and shadehouse light intensity were tested, but none was significant. The data were submitted to two-way ANOVAs by restricted maximum likelihood in order to obtain estimates of within-family and among-families variances. For most traits, there were significant effects of block or leaf state or both (Table 2; only traits showing significant genetic (i.e. family) effects shown), but neither family $\times$ block nor family $\times$ leaf state effects were detected (not shown).

Family effect was significant for nine traits out of 20. Most-likely heritability estimates, along with the upper and lower limits of their $95 \%$ confidence intervals, are displayed in Table 3. Credible Bayesian intervals for total variance were generally relatively narrow, with standard deviation of the estimate generally not exceeding $10 \%$ of the mean (Supplementary Table 1). In subsequent analyses, therefore, most-likely total variance estimates were considered as the "true" variance, and the variation of its estimates was ignored. Most-likely estimators of heritability, for those traits displaying significant nonzero among-families effects, varied between 0.15 (for chlorophyll content index) and 0.28 (for height). For most traits, confidence intervals were wide and very asymmetric, probably due to limited sample size. In spite of this, homologous traits and traits of the same class showed very close most likely values, suggesting that large confidence intervals do not reflect biassed estimates, as provided by likelihood peaks. It is interesting to note that growth traits consistently showed relatively high estimates (between 0.23 and 0.28 ) and that morphological traits showed the smallest values, with most of them being nonsignificantly heritable. Among photosynthesisrelated traits, heritability of photosynthetic rate was not significant, and two chlorophyll content indexes out of three displayed intermediate values of heritability.

Phenotypic correlations were obtained from individual seedling values; genetic correlations were calculated on BLUP estimates of genetic effects. Significant values $(P<$ 0.05 ) are displayed in Table 4. One hundred and twelve phenotypic correlations and 45 genetic correlations were significant; one genetic correlation (L2CC-L3SH) was significant while its phenotypic counterpart was not. All pairs of growth-related traits showed significant genetic and phenotypic correlation, while for physiology-related traits, while all phenotypic correlations were significant, only one genetic correlation (L1CC-L2CC) was. Photosynthetic rate and leaf mass per area were positively and significantly correlated to growth traits, both genetically and phenotypically.

The estimates of AGCV and RCV were plotted against each other and with their combined confidence interval (Fig. 1). When all traits were included in the analysis, AGCV and RCV were correlated with each other $\left(R^{2}=0.68\right.$, $P<10^{-5}$ ), and correlations were higher for traits showing a significant genetic component $\left(R^{2}=0.92, P<10^{-7}\right)$. Spurious correlation caused by scaling and seedling effects was excluded, as neither AGCV nor RCV were correlated to trait means or to sample size (not shown). The confidence intervals were large (Table 4 and Fig. 1) and proportional to the most likely value. In spite of the large uncertainty of the estimates and overall absence of correlation, a clear trend seems to emerge, with traits having large genetic variance also having large residual variance. Homologous traits (chlorophyll content index, leaf thickness) tend to cluster in the same regions of the plot, but growth-related traits are relatively scattered. As expected from the tight correlations of genetic and residual components of variation, narrowsense heritability did not correlate well with $\operatorname{AGCV}\left(R^{2}=\right.$ $0.04, P=0.20$ ).

Based on the genotypes at five SSR loci for the twentyseven open-pollinated families, correlation for the following pairs of estimated were tested for each trait: mother tree 
Table 3 Most-likely estimates of genetic parameters (in parentheses: limits of $95 \%$ confidence intervals $(\mathrm{CI}))$ for traits having significant $(P<0.05)$ additive genetic components

\begin{tabular}{lccc}
\hline & $h^{2}(95 \% \mathrm{CI})$ & AGCV $(95 \% \mathrm{CI})$ & RCV $(95 \% \mathrm{CI})$ \\
\hline Leaf traits & & $0.052(0.028-0.097)$ & $0.11(0.073-0.12)$ \\
L1TH & $0.18(0.052-0.64)$ & $0.038(0.019-0.074)$ & $0.075(0.040-0.082)$ \\
L3TH & $0.20(0.053-0.77)$ & & \\
Growth traits & & $0.061(0.035-0.11)$ & $0.097(0.045-0.11)$ \\
Height & $0.28(0.094-0.85)$ & $0.078(0.043-0.14)$ & $0.14(0.068-0.15)$ \\
Diameter & $0.24(0.073-0.81)$ & $0.080(0.047-0.14)$ & $0.14(0.089-0.16)$ \\
NULF & $0.24(0.080-0.70)$ & $0.20(0.11-0.37)$ & $0.36(0.21-0.40)$ \\
Biomass & $0.24(0.075-0.75)$ & $0.11(0.063-020)$ & $0.21(0.13-0.23)$ \\
LFAR & $0.23(0.073-0.70)$ & & $0.25(0.16-0.26)$ \\
Photosynthesis & & $0.11(0.057-0.22)$ & $0.23(0.097-0.25)$ \\
Traits & & $0.097(0.040-0.23)$ & \\
L1CC & $0.17(0.045-0.66)$ & & \\
L2CC & $0.15(0.025-0.85)$ & &
\end{tabular}

percentage of polymorphic loci and mean family value, mother tree percentage of polymorphic loci and family variance, family observed heterozygosity for each locus and mean family value, family observed heterozygosity for each locus, and family variance. After Bonferroni correction for multiple tests within each trait, no significant correlation was detected. Mother tree polymorphism did not correlate with family means or variances.

\section{Discussion}

The results presented here indicate that most traits associated with plant growth and physiology have significant genetic components in a natural population of a shade-tolerant tropical rainforest tree species. On the other hand, morphological traits showed scant evidence of genetic control. Moderate genetic control for growth traits was also observed in several other quantitative genetic studies carried out on tree species (Cornelius 1994). In a full-sib family of oaks, the narrowsense heritability of total height estimated by ScottiSaintagne et al. (2004) was between 0.05 and 0.45 . In Eucalyptus, genetic variation explained $13 \%$ to $50 \%$ of the global variance (Tripiana et al. 2007). Recently, in openpollinated families of maritime pine, the narrow-sense heritability for total height was estimated to be as high as 0.50 (Bouffier et al. 2008). However, quantitative genetics studies carried out on morphological and physiological traits indicated a rather low genetic control for leaf traits and photosynthetic traits (Brendel et al. 2008; Potts and Jordan 1994; Scotti-Saintagne et al. 2004). This is confirmed by the present study, showing little or no heritability for leaf morphological traits and LMA. Most-likely heritability values fall within the range reported in literature (Callister and Collins 2008; Carnegie et al. 2004; Costa e Silva et al. 2005; Hodge et al. 2002; Navarro et al. 2004; Sotelo Montes et al. 2007; Ward et al. 2008). Growth-related traits, generally speaking, were found to display higher heritability values, often associated with small estimates of genetic and residual coefficients of variation (with the exception of total aboveground biomass). Confidence intervals for genetic parameters were wide, due to sample size, which was severely reduced by early mortality. Measurement of growth traits over a longer period (several years) would permit one to refine estimates of variance components and test whether tree development has an effect on traits.

Heritability estimates may be inflated due to maternal effects. These are notoriously difficult to assess without controlled crosses, which are currently unavailable in $S$. rubra. Anyway, evidence for the influence of potential maternal effects on seedling traits is controversial and highly debated (Bundock et al. 2008; Kormanik et al. 1998; Rae et al. 2008; Wu and Stettler 1994; Zamudio et al. 2005). To attempt to control for these effects, we have assessed the influence of mother tree habitat, as an estimator of nutrient, water availability, and light conditions, and of mother tree size, as an estimator of the general amount of resources that the tree can allocate to seeds. These cofactors had only a limited effect on traits (Table 2), and controlling for them allowed us to only slightly improve estimates of genetic variance. Maternal canopy status, as determined by mother tree $\mathrm{DBH}$, was generally marginally correlated with the measured traits, perhaps suggesting that larger sample sizes may highlight the presence of maternal effects. Another factor that may lead to inflation of heritability estimates is variation in inbreeding or selfing coefficients among families (Hodge et al. 1996). Although no estimate of the variance of selfing is available for this species, Veron et al. (2005) report very high outcrossing rates $\left(t_{\mathrm{m}}=0.992\right)$ for the population as a whole, possibly indicating that variation in inbreeding has only a minor impact on our estimates. 


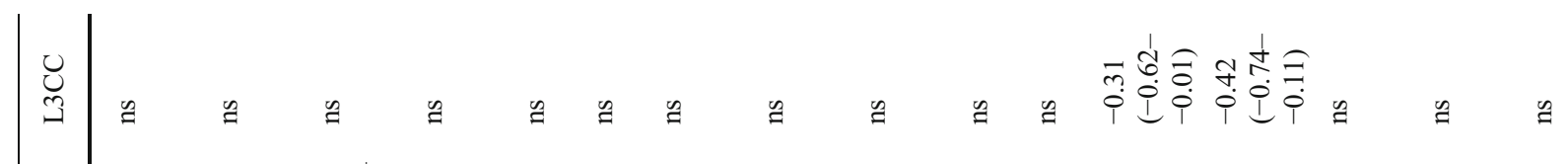

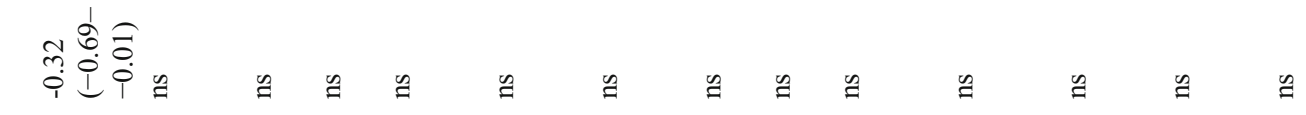

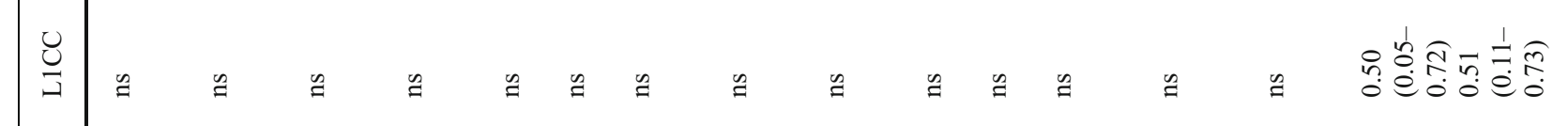

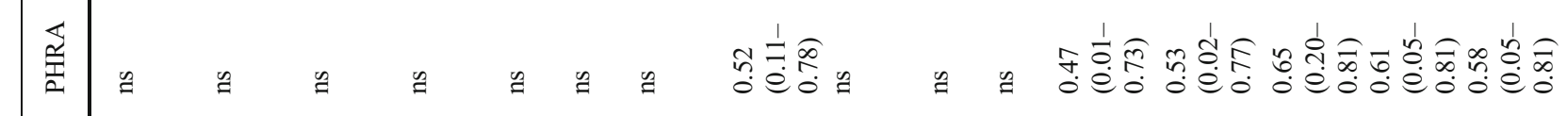

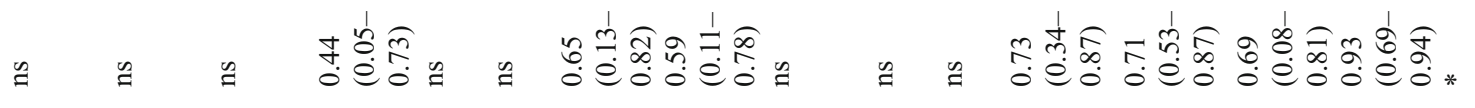

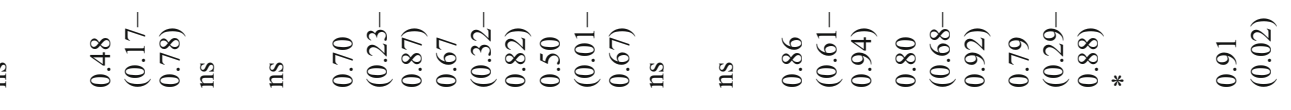

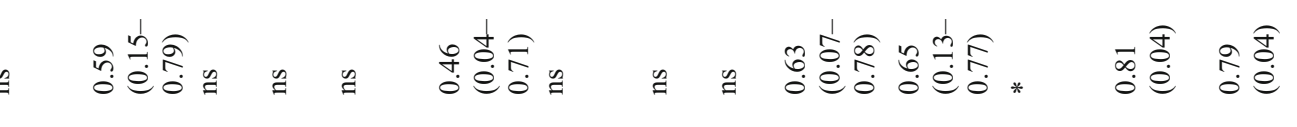

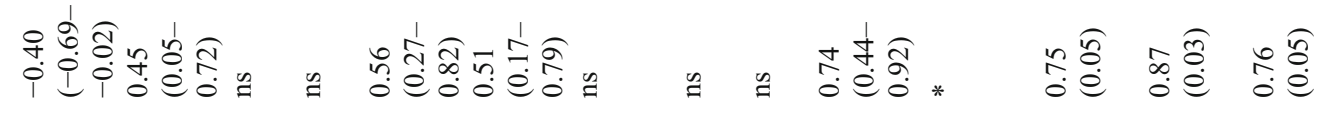

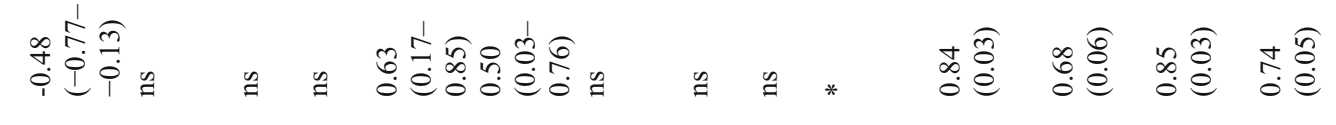
$\cong \quad a \quad \stackrel{i}{=} \stackrel{\hat{i}}{i}$ a

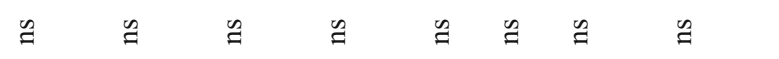

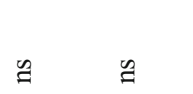

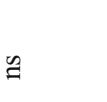

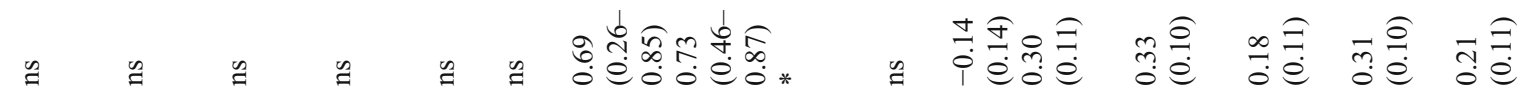

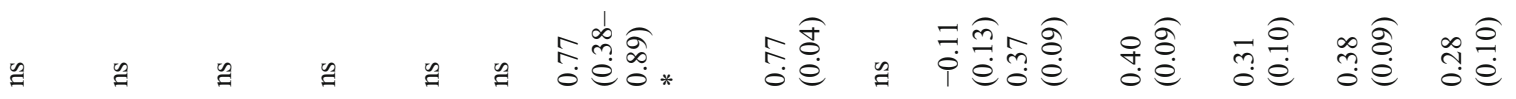

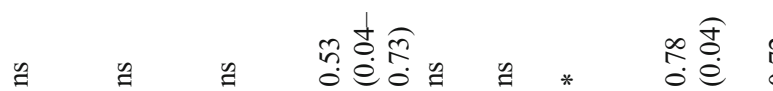
$\because 2$ $\stackrel{2}{=}$

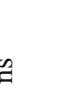
$\cong \quad \mathscr{a}$

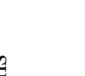
(1) $\approx$

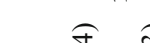

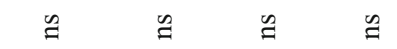
g

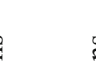

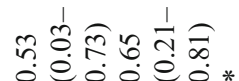

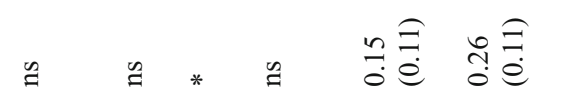
N $\tilde{0}$ ๆ

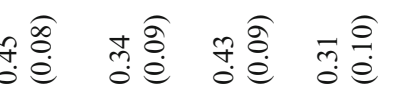
०0.00* a

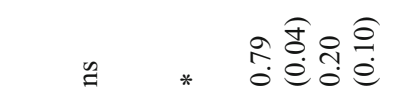

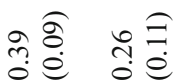
$\cong \cong$

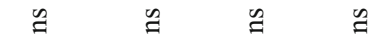

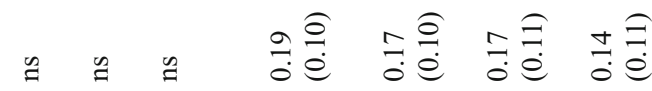

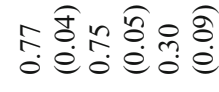

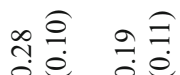
s $\stackrel{0}{\circ}$ กิ

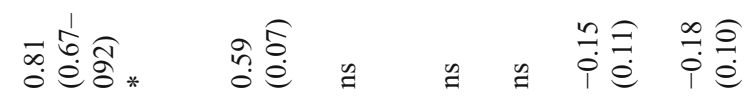
궁 \& $\quad \stackrel{0}{i}$

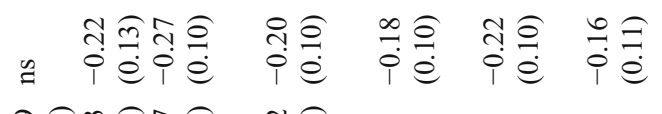
î. 응 a

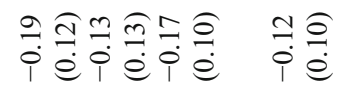
* กำ 蛋 㕃喜 焉 自

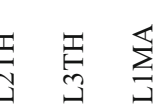




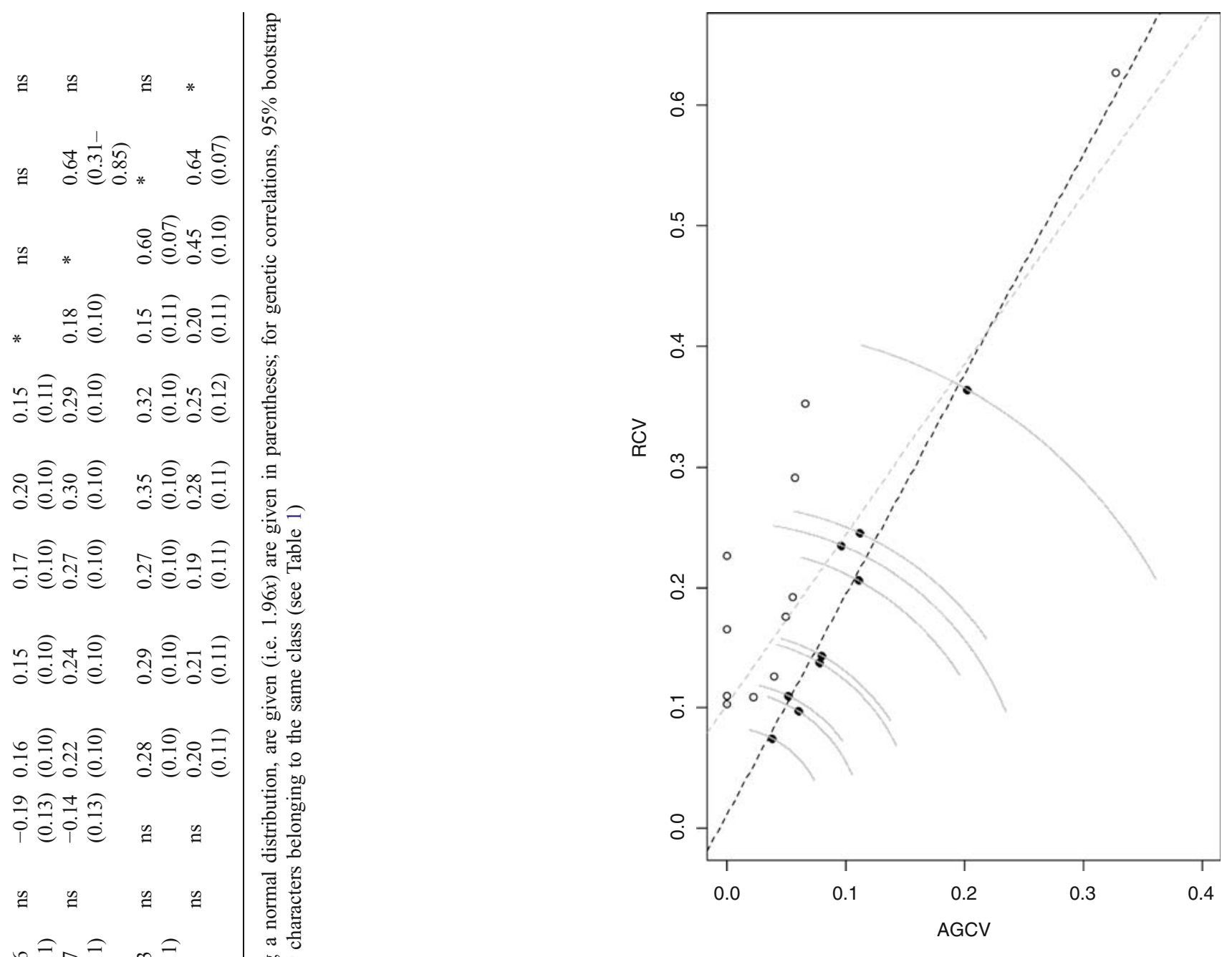

Fig. 1 Plot of estimated residual coefficients of variation $(R C V)$ against additive genetic coefficients of variation $(A G C V)$ and of their joint confidence intervals for traits displaying significant (filled circles) and nonsignificant (open circles) components of additive genetic variance. Grey dashed line regression straight line computed on all traits; black dashed line regression straight line computed on genetically significant traits only

An important factor that could heavily influence the estimation of the relative effect of genetic background and environmental conditions in plants (in particular for photosynthetic traits) is shadehouse light intensity. In natural conditions, the range of light levels experienced by shade-tolerant species is wider than for pioneer species. Therefore, studying the former provides the opportunity of testing genetic $\times$ environment interactions that are not really applicable in the latter. At the same time, our study was limited to only one semicontrolled light level, which means that only one point estimate of genetic and environmental effects, out of a larger range, was obtained. Replicating our experiment in a range of light intensity conditions would allow us to estimate the extent of the range as well as to assess the importance of phenotypic plasticity. Neverthe- 
less, the presence of genetic variability in growth traits, pointing to the existence of faster- and slower-growing open-pollinated families (although well within the range of shade-tolerant species' growth rates), with different leaf anatomical and functional characteristics, raises questions about the possible evolutionary genetic meaning of extant variation.

Correlation analyses showed a general structure with taller S. rubra stems associate with larger stem diameters, a higher number of thicker, more elongated leaves (contributing to a larger total leaf area), and higher chlorophyll content index (Table 4). This seems to hold for both phenotypic and genetic correlations, thus suggesting that these traits share their genetic bases. Interestingly, this does not seem to be the case for physiology-related traits, which show extensive phenotypic correlation but only limited evidence of genetic correlation. In particular, the only significant genetic correlation for any pair of physiological traits occurs between $\mathrm{L} 1 \mathrm{CC}$ and $\mathrm{L} 2 \mathrm{CC}$, which are also the only heritable physiological traits.

Associations of traits have been largely described in the literature, at the global scale (Wright et al. 2004) or at the tropical rainforest scale (Baraloto et al. 2005; Bonal et al. 2007; Santiago and Wright 2007). A negative correlation is usually found at the interspecific level between photosynthesis traits and LMA (Bonal et al. 2007; Coste et al. 2005; Wright et al. 2004), indicating trade-offs among between light and carbon acquisition, on one end, and allocation and growth, on the other end. In contrast, this correlation was positive at the intraspecific level in our study, suggesting that these trade-offs do not hold at the intraspecific level. Interestingly, in European oaks, the only genomic region controlling variation of chlorophyll content index is also involved in the phenotypic variation of LMA, with same sign effects (Brendel et al. 2008), in agreement with a possible positive genetic correlation at the population level.

Genetic and residual coefficients of variation showed significant correlation for traits with significant heritability. This is not necessarily the case, as there is no theoretical reason for additive and residual variance to be biologically linked. Therefore, the observed correlation demands an explanation that our data cannot provide. As a pointer for further investigation, attention should be devoted to nonadditive components of genetic variance, which appear in the present study as a part of residual variance. Considering the high level of genetic diversity observed in S. rubra (Veron et al. 2005), dominance effects may be important through heterozygotes at quantitative trait loci (QTL). However, genetic diversity at neutral loci does not ensure that the same distribution of allele frequencies would apply to QTL.

As a complementary assessment of the genetic base of the observed among-families variation, we investigated the correlation between heterozygosity at random genomic loci, as estimated by neutral molecular markers (SSR), and the distribution of trait values. The analysis was performed with five molecular markers, which is not far from standard procedures for the assessment of genetic diversity in natural populations of forest trees (often performed on fewer than ten loci). Under the hypothesis that heterozygosity promotes better performances (Hansson and Westerberg 2002), it was expected to detect significant correlations between heterozygosity and trait values, although the conditions under which such correlations are found may be very restrictive (Balloux et al. 2004). Alternatively, one may expect that a higher level of heterozygosity implies a larger number of segregating sites, thus leading to correlation between heterozygosity and trait variances. Since no such correlation was found, it can be concluded that either the number of loci used was too small, or that general genomic effects do not contribute to the genetic control of the traits analysed here. In either case, the use of neutral molecular markers as an indication of "genetic quality" is questioned in real cases, and the concept itself that heterozygosity of a given population is correlated with its quantitative genetic properties (a widespread assumption in the assessment of the conservation status of forest tree populations) finds no support in this study; these conclusions echo the findings of Vendramin et al. (2008) which showed that low levels of diversity at neutral markers were uncorrelated to the adaptive potential of a widely distributed tree species.

In conclusion, although our results are not conclusive, they suggest that individual genetic variation should be taken into account when dealing with population properties in ecological studies of tropical rainforest trees and communities. For management purposes, it seems that selection based on open-pollinated families would be efficient at least for most growth traits, which show relatively high heritability, but, on the other hand, neutral markers provide little help (at least when a limited number is used) in the evaluation of genetic material. Given the importance of survival and growth at early stages in the highly competitive rainforest environment, these results may have direct consequences for the modelling of ecological genetic processes. On the other hand, their extrapolation to management practices requires further investigation to disclose the relationship between traits at the seedling and the adult stages.

Acknowledgements The authors wish to thank Saintano Dufort and Saint-Omer Cazal for help with plant handling and shadehouse work, Jean-Yves Goret and Valérie Troispoux for their contribution to the photosynthesis measurements, Antoine Kremer, Pauline Garnier-Géré, and Christopher Baraloto for useful discussions, and François Lefèvre and three anonymous reviewers for critically reading the manuscript. 


\section{References}

Augspurger CK, Kitajima K (1992) Experimental studies of seedling recruitment from contrasting seed distributions. Ecology 73:1270-1284

Balloux F, Amos W, Coulson T (2004) Does heterozygosity estimate inbreeding in real populations? Mol Ecol 13:3021-3031

Baraloto C, Goldberg D, Bonal D (2005) Performance trade-offs among tropical tree seedlings in contrasting microhabitats. Ecology 86:2461-2472

Baraloto C, Bonal D, Goldberg D (2006) Differential seedling growth response to soil resource availability among nine Neotropical tree species. J Trop Ecol 22:487-497

Barigah TS, Imbert P, Huc R (1998) Growth and net assimilation rate of seedlings of ten Guianan tree species grown under five light regimes. Ann For Sci 55:681-706

Bonal D, Born C, Brechet C et al (2007) The successional status of tropical rainforest tree species is associated with differences in leaf carbon isotope discrimination and functional traits. Ann For Sci 64:169-176

Bouffier L, Raffin A, Kremer A (2008) Evolution of genetic variation for selected traits in successive breeding populations of maritime pine. Heredity 101:156-165

Brendel O, Le Thiec D, Scotti-Saintagne C et al (2008) Quantitative trait loci controlling water use efficiency and related traits in Quercus robur L. Tree Genet Genom 4:263-278

Bundock P, Potts B, Vaillancourt R (2008) Detection and stability of quantitative trait loci (QTL) in Eucalyptus globulus. Tree Genet Genom 4:85-95

Callister A, Collins S (2008) Genetic parameter estimates in a clonally replicated progeny test of teak (Tectona grandis Linn. f.). Tree Genet Genom 4:237-245

Carnegie A, Johnson I, Henson M (2004) Variation among provenances and families of blackbutt (Eucalyptus pilularis) in early growth and susceptibility to damage from leaf spot fungi. Can J For Res 34:2314-2326

Cornelius J (1994) Heritabilities and additive genetic coefficients of variation in forest trees. Can J For Res 24:372-379

Costa e Silva J, Dutkowski G, Borralho N (2005) Across-site heterogeneity of genetic and environmental variances in the genetic evaluation of Eucalyptus globulus trials for height growth. Ann For Sci 62:183-191

Coste S, Roggy J-C, Imbert P et al (2005) Leaf photosynthetic traits of 14 tropical rain forest species in relation to leaf nitrogen concentration and shade tolerance. Tree Physiol 25:1127-1137

Favrichon V (1994) Classification des espèces arborées en groupes fonctionnels en vue de la réalisation d'un modèle de dynamique de peuplement en forêt Guyanaise. Revue écologique (Terre et Vie) 49:379-403

Hansson B, Westerberg L (2002) On the correlation between heterozygosity and fitness in natural populations. Mol Ecol 11:2467-2474

Hardy OJ, Maggia L, Bandou E et al (2006) Fine-scale genetic structure and gene dispersal inferences in 10 Neotropical tree species. Mol Ecol 15:559-571

Hodge G, Dvorak W, Urueña H et al (2002) Growth, provenance effects and genetic variation of Bombacopsis quinata in field tests in Venezuela and Colombia. For Ecol Manag 158:273-289
Hodge GR, Volker PW, Potts BM et al (1996) A comparison of genetic information from open-pollinated and control-pollinated progeny tests in two Eucalyptus species. Theor Appl Genet 92:53-63

Kormanik P, Sung S, Kormanik T et al (1998) Effect of acorn size on development of northern red oak 1-0 seedlings. Can J For Res 28:1805-1813

Lynch M, Walsh B (1998) Genetics and analysis of quantitative traits. Sinauer, Sunderland, MA

Navarro C, Montagnini F, Hernández G (2004) Genetic variability of Cedrela odorata Linnaeus: results of early performance of provenances and families from Mesoamerica grown in association with coffee. For Ecol Manag 192:217-227

Poorter L, Markesteijn L (2008) Seedling traits determine drought tolerance of tropical tree species. Biotropica 40:321-331

Potts B, Jordan G (1994) Genetic variation in the juvenile leaf morphology of Eucalyptus globulus Labill. ssp. globulus. For Genet 1:81-95

Rae A, Pinel M, Bastien C et al (2008) QTL for yield in bioenergy Populus: identifying $\mathrm{G} \times \mathrm{E}$ interactions from growth at three contrasting sites. Tree Genet Genom 4:97-112

Santiago LS, Wright SJ (2007) Leaf functional traits of tropical forest plants in relation to growth form. Funct Ecol 21:19-27

Scotti-Saintagne C, Bodénès C, Barreneche T et al (2004) Detection of quantitative trait loci controlling bud burst and height growth in Quercus robur L. Theor Appl Genet 109:1648-1659

Sotelo Montes C, Beaulieu J, Hernández RE (2007) Genetic variation in wood shrinkage and its correlations with tree growth and wood density of Calycophyllum spruceanum at an early age in the Peruvian Amazon. Can J For Res 37:966-976

Sterck FJ, Poorter L, Schieving F (2006) Leaf traits determine the growth-survival trade-off across rain forest tree species. Am Nat 167:758-765

Tripiana V, Bourgeois M, Verhaegen D et al (2007) Combining microsatellites, growth, and adaptive traits for managing in situ genetic resources of Eucalyptus urophylla. Can J For Res 37:773-785

Vendramin GG, Fady B, Gonzalez-Martinez SC et al (2008) Genetically depauperate but widespread: the case of an emblematic Mediterranean pine. Evolution 62:680-688

Veron V, Caron H, Degen B (2005) Gene flow and mating system of the tropical tree Sextonia rubra. Silvae Genet 54:275-280

Ward S, Wightman K, Rodriguez Santiago B (2008) Early results from genetic trials on the growth of Spanish cedar and its susceptibility to the shoot borer moth in the Yucatan Peninsula, Mexico. For Ecol Manag 255:356-364

Wightman K, Ward SE, Haggar J et al (2007) Performance and genetic variation of big-leaf mahogany (Swietenia macrophylla King) in provenance and progeny trials in the Yucatan Peninsula of Mexico. For Ecol Manag 255:346-355

Wright IJ, Reich PB, Westoby M et al (2004) The worldwide leaf economics spectrum. Nature 428:821-827

Wu R, Stettler RF (1994) Quantitative genetics of growth and development in Populus. I. A three-generation comparison of tree architecture during the first 2 years of growth. TAG Theor Appl Genet 89:1046-1054

Zamudio F, Rozenberg P, Baettig R et al (2005) Genetic variation of wood density components in a radiata pine progeny test located in the south of Chile. Ann For Sci 62:105-114 